\title{
An application of fuzzy TOPSIS on ranking products: A case study of faucet devices
}

\author{
Seyed Hasan Kia ${ }^{a^{*}}$, Abolfazl Danaei ${ }^{\mathrm{b}}$ and Mehrdad Oroei ${ }^{\mathrm{b}}$
}

${ }^{a}$ Young Researchers and Elite Club Semnan Branch, Islamic Azad University, Semnan, Iran ${ }^{b}$ Department of Management, Semnan Branch, Islamic Azad University, Semnan, Iran

\section{H R O N I C L E}

Article history:

Received January 15, 2013

Accepted August 17, 2013

Available online

August 182013

Keywords:

Fuzzy TOPSIS

Ranking method

Faucet

\section{A B S T R A C T}

\begin{abstract}
During the past two decades, there have been some concerns on application of multiple criteria decision making on prioritizing production planning. In this paper, we present an empirical investigation to use Technique of ranking by similarity by positive ideal solution (TOPSIS) for ranking various alternatives productions in an Iranian firm in Faucet industry named Irandoosh. The proposed study uses fuzzy numbers to handle uncertainty and using five criteria of profitability, life cycle, quality, social issues and production capacity, analytical hierarchy process is employed to rank various alternatives and then rank different products based on TOPSIS technique.
\end{abstract}

(C) 2014 Growing Science Ltd. All rights reserved.

\section{Introduction}

Ranking different alternatives has become one of the most important issues among decision makers and there are various studies associated with ranking industrial products (Sadi-Nezhad \& ShahnazariShahrezaei, 2013). Technique of ranking by similarity by positive ideal solution (TOPSIS) is one of the most popular techniques for ranking various alternatives (Hwang \& Yoon, 1981; Zaheri et al., 2012). Data envelopment analysis (DEA) is another popular technique for measuring the relative performance of similar units (Charnes et al., 1978, 1994). Hemmati et al. (2013), for instance, used a hybrid of these two techniques to measure the relative efficiencies of 16 private and governmental Iranian banks in terms of electronic payment. Khodaei Valahzaghard and Ansar (2013) measured relative performance of banking industry using a DEA and TOPSIS and compared the results with each other.

\footnotetext{
* Corresponding author.

E-mail addresses: Kia_hasan1369@yahoo.com (S. H. Kia)

(C) 2013 Growing Science Ltd. All rights reserved. doi: $10.5267 /$ j.ds1.2013.08.004
} 
Azad and Hassanabadi (2013) presented an empirical investigation on factors influencing on brand loyalty. They used structural equation modeling to detect important factors and they were ranked using TOPSIS method. There were eight influencing factors including flexibility in offering various services, building good relationship with customers, technology and processes, customers' experiences, brand identity in continuous advertisement, organization size, customer perception on reputation of brand and customers' tendency to build better brand loyalty. In this survey, flexibility in offering various services received the highest rank followed by building good relationship with customers.

Afkham et al. (2012) explained the importance of service quality in health care systems and presented an effective technique for evaluating and comparing service qualities of four hospitals in Iran. In their method, service quality consisted of various attributes and many of them were intangible and difficult to measure. Therefore, they proposed a fuzzy method to resolve the ambiguity of the concepts, which were associated with human judgments. SERVQUAL model was used to evaluate the respondents' judgments of service quality and multi attribute decision making approach was implemented for the comparison among hospitals. The paper used analytical hierarchy process (AHP) for obtaining criteria weight and TOPSIS for ranking the cases.

Jannatifar et al. (2012) discusses that Intellectual capital is a kind of asset measuring ability of economic agency in order to make wealth and presented a survey based on Fuzzy TOPSIS to find important factors influencing intellectual capital management. They considered different factors, which exist in the literature and prioritize them based on different criteria and the results of the survey identified several items as the most influencing factors. Orougi et al. (2012) used TOPSIS method for ranking technological solar-geothermal hybrid energy system. Nazari et al. (2012) used TOPSIS for ranking different national Iranian oil refining and distribution companies.

\section{The proposed method}

Technique of ranking by similarity by positive ideal solution (TOPSIS) is considered as a classical multiple criteria decision-making (MCDM) method, which was first developed by Hwang and Yoon (1981). The selected alternative should keep the shortest distance from the positive ideal solution and, on the other side, the farthest distance from the negative ideal solution (Hwang \& Yoon, 1981). Fuzzy TOPSIS technique in Iran started from 1990s in a restricted form and some instances of its application are limited to the recent years. The proposed model of this paper uses fuzzy triangular numbers, which is specified as follows (Zadeh, 1965),

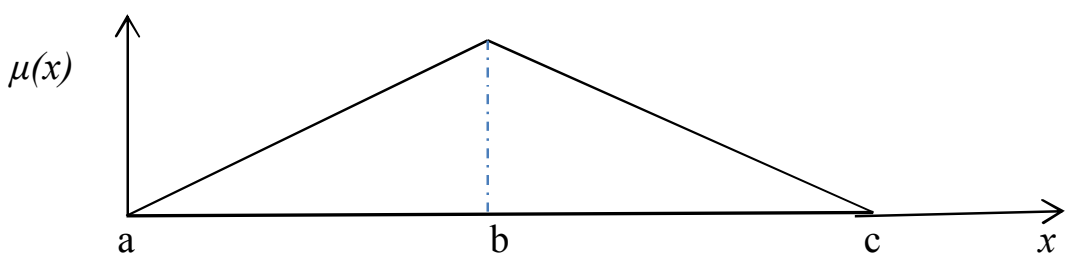

Fig. 1. The fuzzy triangular number

According to Ahani et al. (2013), decision making process steps by fuzzy TOPSIS technique are as follows:

Step 1: Calculating weights vector $w_{j}$

Step 2: Normalizing the matrix obtained from experts opinions regarding the alternatives, which forms a new matrix as the follows: 
$\widetilde{R}=\left[\widetilde{r}_{i j}\right]_{m \times n}$

$B \subseteq\{1, \ldots, n\}$ refers to the interest indices (2) and $C \subseteq\{1, \ldots, n\}$ refers to the cost indices (3).

$\tilde{r}_{i j}=\left(\frac{a_{i j}}{d_{j}^{+}}, \frac{b_{i j}}{d_{j}^{+}}, \frac{c_{i j}}{d_{j}^{+}}\right), \quad j \in B \quad d_{j}^{+}=\max _{i} d_{i j} \quad$ if $j \in B$

$\tilde{r}_{i j}=\left(\frac{a_{j}^{-}}{d_{i j}}, \frac{a_{j}^{-}}{c_{i j}}, \frac{a_{j}^{-}}{b_{i j}}\right), \quad j \in C$

$a_{j}^{-}=\min _{i} a_{i j} \quad$ if $j \in C$

Step 3: So normalized weighted matrix is calculated as Eq. (4):

$\tilde{V}=\left[\tilde{v_{i j}}\right]_{m \times n}, \quad i=1,2, \ldots, m, j=1,2, \ldots, n \tilde{v_{i j}}=\tilde{r}_{i j} \otimes \tilde{w}_{j}$

Step 4: Determining the fuzzy positive ideal solution $(F P I S)^{\tilde{r}_{j}^{*}}$ and fuzzy negative ideal solution $(F N I S)^{\tilde{V}_{j}^{-}}$(Eq. (5) and Eq. (6)):

$\tilde{v}_{j}^{+}= \begin{cases}\max & \tilde{v_{i j}} ; j \in B \\ i=1 \ldots, m & \\ \min & \tilde{v}_{i j} ; j \in C \\ i=1 \ldots, m & \end{cases}$

$F P I S=\left\{\tilde{v}_{j}^{+} \mid j=1, \ldots, n\right\}$

$\widetilde{v}_{j}^{-}= \begin{cases}\min & \tilde{v}_{i j} ; j \in B \\ i=1 \ldots, m & \\ \max & \widetilde{v}_{i j} ; j \in C \\ i=1 \ldots, m & \end{cases}$

$F N I S=\left\{\tilde{v}_{j}^{-} \mid j=1, \ldots, n\right\}$

Step 5: Calculating the distances using Fuzzy Euclidian distance:

$D(\tilde{a}, \tilde{b})=\sqrt{\frac{1}{3}\left[\left(a_{1}-b_{1}\right)^{2}+\left(a_{2}-b_{2}\right)^{2}+\left(a_{3}-b_{3}\right)^{2}\right]}$

The distance of each alternative from positive and negative ideal is calculated by applying Eq. (8) and Eq. (9) as follows,

$S_{i}^{+}=\sum_{j=1}^{n} D\left(\tilde{v}_{i j}, v_{j}^{+}\right), \quad i=1,2, \ldots, m$, 
$S_{i}^{-}=\sum_{j=1}^{n} D\left(\tilde{v}_{i j}, v_{j}^{-}\right), \quad i=1,2, \ldots, m$,

Step 6: Calculate the relative closeness to the ideal solution and ranking given in Eq. (10):

$C c_{i}=\frac{S_{i}^{-}}{S_{i}^{+}+S_{i}^{-}}, \quad i=1,2, \ldots, m$

\section{The case study}

The proposed study of this paper uses Fuzzy TOPSIS method for one of Iranian Faucet producers named Irandoosh. The history of Irandoosh goes back to 1977 when building faucets industry was a brand new industry in the country. In fact, Irandoosh is one of the pioneers of health and building faucets in Iran and even in Middle East. The company is one of a few factories in country, which is able to perform all production processes including casting, matching, polishing, planning and packing using full-automatic state of the art machinery, independently. Fig. 2 shows some of the products of this firm.
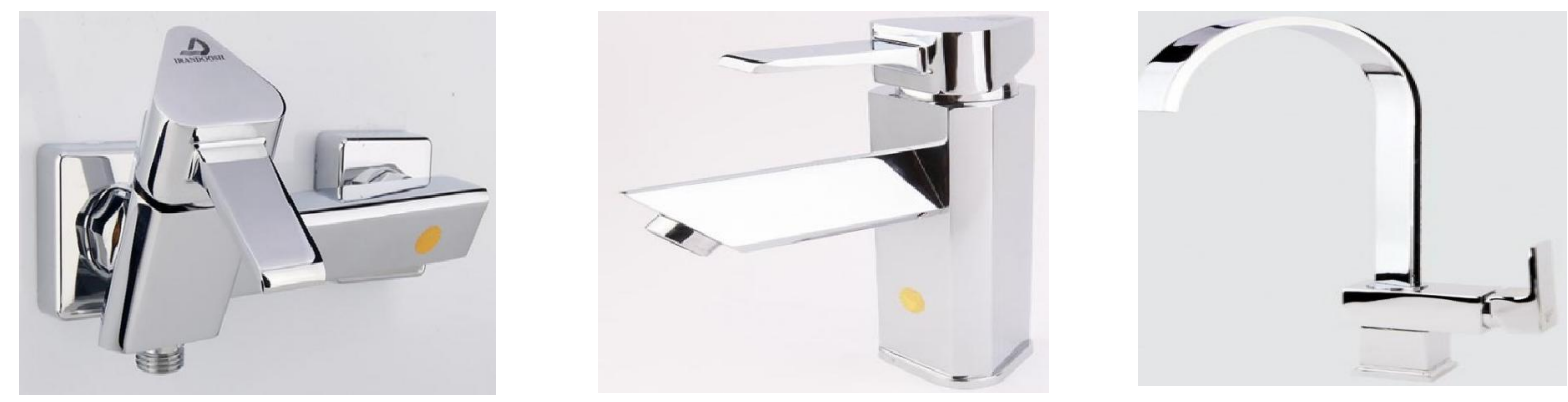

Fig. 2. Sample products

In this study, we consider three different types of single lever basin products used for kitchen, shower and washroom and using Fuzzy TOPSIS we rank them based on five criteria of profitability, life time, quality, social factors and production capacity. In our study, we have gathered decision makers' feedback and using analytical hierarchy process (AHP), we have ranked them. Table 1 demonstrates the summary of our findings,

Table 1

The results of ranking different alternatives using AHP method

\begin{tabular}{lccccc}
\hline Criterion & Profitability & Life cycle & Quality & Social factors & Production capacity \\
\hline Rank & 0.49 & 0.26 & 0.13 & 0.09 & 0.03 \\
\hline
\end{tabular}

As we can observe from the results of Table 1, profitability is number one priority followed by life cycle, quality, social factors and production capacity. The implementation of Fuzzy TOPSIS explained is previous section provides details of ranking for three products, which are summarized in Table 2 as follows,

Table 2

The summary of ranking three types of products in terms fuzzy triangular numbers

\begin{tabular}{lccccc}
\hline Criterion & Profitability & Life time & Quality & Social factors & Production capacity \\
\hline $\begin{array}{l}\text { Single lever } \\
\text { washroom basin }\end{array}$ & $(0.5,0.25,1)$ & $(0.5,0.25,1)$ & $(0.2,0.8,0.75)$ & $(0.2,0.8,0.85)$ & $(0.8,0.65,0.7)$ \\
$\begin{array}{l}\text { Single lever } \\
\text { shower basin }\end{array}$ & $(0.7,0.5,0.3)$ & $(0.5,0.75, .9)$ & $(0.5,0.75,0.9)$ & $(0.4,0.5,0.6)$ & $(0.7,0.9,0.2)$ \\
$\begin{array}{l}\text { Single lever } \\
\text { basin mixer }\end{array}$ & $(0.7,0.75, .8)$ & $(0.5,0.75, .9)$ & $(0.5, .75,0.9)$ & $(0.4,0.5,0.6)$ & $(0.5,0.75,0.9)$ \\
\hline
\end{tabular}


Applying the weights gathered from Table 1, it is possible to combine all five criteria and find the final weights for three mentioned products. The results indicate that single lever basin mixer is number one priority for production followed by single level shower basin and single level washroom basin comes last in terms of priority.

\section{Conclusion}

In this paper, we have presented an empirical investigation to find important factors influencing product development in faucet industry. The study has implemented analytical hierarchy process to make a pairwise comparison among five important factors, namely profitability, life cycle, quality, social issues and production capacity. The results have indicated that profitability is the most important factors followed by product life cycle, quality, social factors and production capacity. Since these five figures are somehow vague to determine for each product, we used triangular fuzzy numbers for measuring the relative importance of each factor for each product.

\section{Acknowledgement}

The authors would like to thank anonymous referees for constructive comments on earlier version of the paper.

\section{References}

Afkham, L., Abdi, F., \& Rashidi, A. (2012). Evaluation of service quality by using fuzzy MCDM: A case study in Iranian health-care centers. Management Science Letters, 2(1), 291-300.

Ahani, M., Bahrami, H.R., \& Rostami, M. (2013). Determining and ranking dimensions of knowledge management implementation using Hicks model and fuzzy TOPSIS Technique. Management Science Letters, 3(2), 721-730.

Azad, N., \& Hassanabadi, M. (2013). An empirical investigation on factors influencing on brand loyalty. Management Science Letters, 3(7), 2113-2118.

Charnes, A, Cooper, W. W., Rhodes, E. (1978). Measuring the efficiency of decision making units. European Journal of the Operational Research, 2, 429-44.

Charnes, A, Cooper W. W., Lewin, A., Seiford, L. M. (1994). Data envelopment analysis: theory, methodology and applications. Massachusetts: Kluwer Academic Publishers.

Chen, C.T. (2000). Extension of the TOPSIS for group decision- making under fuzzy environment. Fuzzy Sets and Systems, 114, 1-9.

Hemmati, M., Dalghandi, S.A., \& Nazari, H. (2013). Measuring relative performance of banking industry using a DEA and TOPSIS. Management Science Letters, 3(2), 499-504.

Hwang, C. L., \& Yoon, K. (1981). Multiple attribute decision making: Methods and applications. Berlin, Springer.

Jannatifar, H., KazemKeshvar Shahi, M., \& Siahkali Moradi, J. (2012). Assessing intellectual capital management by fuzzy TOPSIS. Management Science Letters, 2(6), 1991-2000.

Khodaei Valahzaghard, M., \& Ansar, M. (2013). Measuring relative performance of banking industry using a DEA and TOPSIS. Management Science Letters, 3(2), 527-532.

Nazari, I., Vakil Alroaia, Y., \& Bahraminasab, S. (2012). An application of multiple criteria decisionmaking techniques for ranking different national Iranian oil refining and distribution companies. Management Science Letters, 2(7), 2341-2346.

Orougi, S., Esmailzade Maghari, A., Mohammadi, H., Gol Mohammadi, A.M., \& Irani, M. (2012). An empirical investigation to use solar-geothermal hybrid energy system for small towns. Management Science Letters, 2(7), 2287-2292.

Sadi-Nezhad, S \& Shahnazari-Shahrezaei, P. (2013). Ranking fuzzy numbers using preference ratio: A utility function approach. Decision Science Letters, 2(3), 149-162. 
Saaty, T.L. (1980). The Analytic Hierarchy Process. McGraw Hill Publications.

Saaty, T.L. (1994). How to make a decision: The analytic hierarchy process. Interfaces, 24(6), 19-43. Zadeh, L.A. (1965). Fuzzy sets. Information and Control, 8(3), 338-353.

Zaheri, F., Farughi, H., Soltanpanah, H., Alaniazar, S., \& Naseri, F. (2013). Evaluation of service quality by using fuzzy MCDM: A case study in Iranian health-care centers. Management Science Letters, 2(2), 697-704. 